\title{
Efficient Preparation of N-Phenylsulfenyl Ketimines from Oximes or Nitro Compounds without Racemization of - Stereocenters
}

DOI:

10.1021/ol702212n

Link to publication record in Manchester Research Explorer

Citation for published version (APA):

Burés, J., Isart, C., \& Vilarrasa, J. (2007). Efficient Preparation of N-Phenylsulfenyl Ketimines from Oximes or Nitro Compounds without Racemization of -Stereocenters. Organic Letters, 9, 4635-4638.

https://doi.org/10.1021/ol702212n

Published in:

Organic Letters

\section{Citing this paper}

Please note that where the full-text provided on Manchester Research Explorer is the Author Accepted Manuscript or Proof version this may differ from the final Published version. If citing, it is advised that you check and use the publisher's definitive version.

\section{General rights}

Copyright and moral rights for the publications made accessible in the Research Explorer are retained by the authors and/or other copyright owners and it is a condition of accessing publications that users recognise and abide by the legal requirements associated with these rights.

\section{Takedown policy}

If you believe that this document breaches copyright please refer to the University of Manchester's Takedown Procedures [http://man.ac.uk/04Y6Bo] or contact uml.scholarlycommunications@manchester.ac.uk providing relevant details, so we can investigate your claim.

\section{OPEN ACCESS}




\title{
Efficient Preparation of $\mathrm{N}$-Phenylsulfenyl Ketimines from Oximes or Nitro Compounds without Racemization of $\alpha$-Stereocenters
}

2007

Vol. 9, No. 22

$4635-4638$

\author{
Jordi Burés, Carles Isart, and Jaume Vilarrasa* \\ Departament de Química Orgànica, Facultat de Química, Universitat de Barcelona, \\ 08028 Barcelona, Catalonia, Spain
}

jvilarrasa@ub.edu

Received September 8, 2007

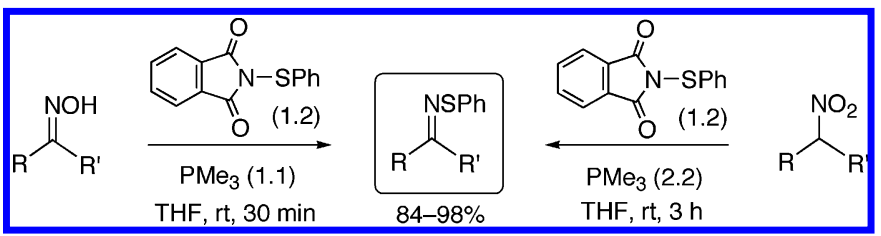

As $\mathrm{N}$-sulfenyl imines (e.g., $R R^{\prime} \mathrm{C}=\mathrm{N}-\mathrm{SAr}$ ) can be readily transformed to their $\mathrm{N}$-sulfinyl imines $\left(\mathrm{RR} \mathbf{R}^{\prime} \mathrm{C}=\mathrm{N}-\mathrm{SOAr}\right), \mathrm{N}$-sulfonyl imines $\left(\mathrm{RR} \mathbf{C}^{\prime} \mathrm{C}=\right.$ $\mathrm{N}-\mathrm{SO}_{2} \mathrm{Ar}$ ), and $\mathrm{N}$-sulfonyl oxaziridines, the very mild procedure developed to convert ketoximes and secondary nitro derivatives to $\mathrm{N}$-arenesulfenyl ketimines constitutes a new and efficient route to all these series of compounds. The configuration of the $\alpha$-stereocenters is retained.

$N$-Sulfinyl imines ${ }^{1,2}$ and $N$-sulfonyl imines ${ }^{3,4}$ are enjoying an increasing number of applications in asymmetric synthesis (Mannich reactions, $\alpha$-alkylation via enamine anions, heteroDiels - Alder reactions, etc.). Chiral $N$-sulfonyl oxaziridines

(1) Reviews: (a) Morton, D.; Stockman, R. A. Tetrahedron 2006, 62, 8869. (b) Zhou, P.; Chen, B.-C.; Davis, F. A. Tetrahedron 2004, 60, 8003 (4-toluenesulfinyl imines). (c) Ellman, J. A.; Owens, T. D.; Tang, T. P. Acc. Chem. Res. 2002, 35, 984 ('BuSO-N=CRR'). Also see: (d) Ellman, J. A. Pure Appl. Chem. 2003, 75, 39.

(2) For very recent, representative papers, see: (a) Davis, F. A.; Song, M. Org. Lett. 2007, 9, 2413. (b) Davis, F. A.; Zhang, Y.; Qiu, H. Org. Lett. 2007, 9, 833. (c) Tanuwidjaja, J.; Peltier, H. M.; Ellman, J. A. J. Org. Chem. 2007, 72, 626. (d) Pei, D.; Wang, Z.; Wei, S.; Zhang. Y.; Sun, J. Org. Lett. 2006, 8, 5913. (e) Xiao, X.; Wang, H.; Huang, Z.; Yang, J.; Bian, X.; Qin, Y. Org. Lett. 2006, 8, 139. (f) Peltier, H. M.; Ellman, J. A J. Org. Chem. 2005, 70, 7342. (g) Lanter, J. C.; Chen, H.; Zhang, X.; Sui, Z. Org. Lett. 2005, 7, 5905. (h) McMahon, J. P.; Ellman, J. A. Org. Lett. 2005, 7, 5393. (i) García-Ruano, J. L.; Topp, M.; López-Cantarero, J.; Alemán, J.; Remuiñán, M. J.; Cid, M. B. Org. Lett. 2005, 7, 4407.

(3) Reviews: (a) Gohain, M. Synlett 2003, 13, 2097. (b) Weinreb, S. M. Top. Curr. Chem. 1997, 190, 131.

(4) For very recent, representative papers, see: (a) Matsubara, R.; Doko, T.; Uetake, R.; Kaboyashi, S. Angew. Chem., Int. Ed. 2007, 46, 3047. (b) Ghorai, M. K.; Kumar, A.; Halder, S. Tetrahedron 2007, 63, 4779. (c) Esquivias, J.; Gómez-Arrayás, R.; Carretero, J. C. J. Org. Chem. 2005, 70, 745. (d) Mancheno, O. G.; Arrayas, R. G.; Carretero, J. C. J. Am. Chem. Soc. 2004, 126, 456. (e) Wang, C.-J.; Shi, M. J. Org. Chem. 2003, 68, 6229. are also very popular as asymmetric epoxidation and hydroxylation reagents. ${ }^{5}$ As known, ${ }^{6} N$-sulfenyl imines such as sulfenimines $\mathbf{1}$ are easily oxidized with $m$-CPBA or other peroxyacids to $N$-sulfinyl derivatives (sulfinimines 2), subsequently to their $N$-sulfonyl derivatives (sulfonimines $\mathbf{3}$ ), and then to $N$-sulfonyl oxaziridines (4); ${ }^{6}$ therefore, any efficient entry to $\mathbf{1}$ would be extremely useful. ${ }^{7}$ This is simplified in Scheme 1, where only one stereoisomer is drawn for each species. ${ }^{8}$ We have focused our attention on ketimines, which have been studied much less than aldimines.

In fact, the success of many asymmetric reactions involving $\mathbf{2}-\mathbf{4}$ relies upon their preparation as stereopure substrates and their configurational stability. Usually, $N$-sulfinyl ketimines are prepared by condensation of ketones and sulfenamides $\left(\mathrm{RSONH}_{2}\right.$ or $\left.\mathrm{ArSONH}_{2}\right)$ mediated by $\mathrm{Ti}(\mathrm{OEt})_{4}$ or other

(5) Reviews: (a) Mishra, J. K. Synlett 2005, 543. (b) Davis, F. A.; Chen, B. C. Chem. Rev. 1992, 92, 919. Also see: (c) García-Ruano, J. L.; Alemán, J.; Fajardo, C.; Parra, A. Org. Lett. 2005, 7, 5493.

(6) Historical review: Davis, F. A. J. Org. Chem. 2006, 71, 8993.

(7) In a very recent example, in which condensation of a sulfinamide with a carbonyl group of an avermectin failed, the authors took advantage of the oxime-to-sulfenimine conversion. See: Lamy, E.; Lüthi, P.; Paturel, C.; Winkler, T.; Jung, P. M. J. Tetrahedron Lett. 2006, 47, 5657.

(8) In addition, $\mathrm{R}$ and/or $\mathrm{R}^{\prime}$ may contain stereogenic centers. 
Scheme 1. From Sulfenyl Imines to $N$-Sulfonyl Oxaziridines

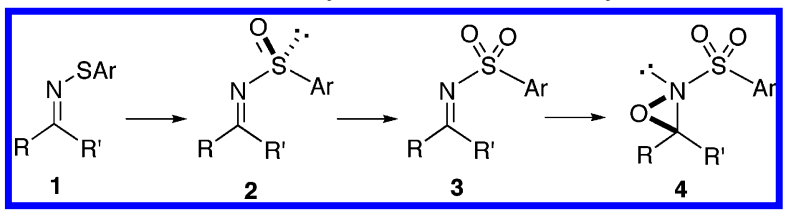

dehydrating agents in refluxing $\mathrm{THF}^{9}$ but also by the abovementioned oxidation of $N$-sulfenyl ketimines and by the reaction ${ }^{10}$ of metal iminides with sulfinates (RSOOR'). $\mathrm{N}$-Sulfonyl ketimines are mainly obtained by condensation (with limitations) of sulfonamides and ketones, ${ }^{3,4}$ from oximes and sulfonyl cyanides, ${ }^{11}$ and by oxidation of $\mathrm{N}$ sulfinyl ketimines. ${ }^{12}$

We uncover a very mild method that gives practically quantitative yields of the desired sulfenimines $\mathbf{1}$ at room temperature (rt) from ketoximes and from secondary nitro compounds. It is a significant practical improvement with regard to the reaction of oximes with $\mathrm{PBu}_{3} / \mathrm{PhSSPh}$ reported by Lukin and Narayanan; ${ }^{13 a}$ these authors showed that sulfenyl ketimines are intermediates in the conversion of oximes to imines ${ }^{13 b}$ and can be cleaved in the presence of suitable acids. Our procedure can be very useful when the direct condensation to obtain $\mathbf{2}$ and $\mathbf{3}$ fails $^{7}$ because of the steric hindrance or when it is counter-indicated as concomitant reactions (including stereocenter inversions) take place in the $\mathrm{R}$ or $\mathrm{R}^{\prime}$ chains.

When the oximes in Table 1 (usually equilibrium $Z / E$ mixtures) were treated with commercially available $N$ (phenylsulfenyl)phthalimide, that is, $N$-(phenylthio)phthalimide (PhthN-SPh, a non-stinking solid) and trimethylphosphine $\left(\mathrm{PMe}_{3}\right)$ at $\mathrm{rt}, \mathrm{N}$-phenylsulfenyl ketimines $\mathbf{1 a}-\mathbf{g}$ were formed quickly. Direct separation and purification of the final mixtures through a short pad of alumina, with hexane as the eluent, afforded excellent isolated yields (86-97\%, see Table $1)$, with no stench, as PhSH was not formed as a co-product or during the workup. $\alpha$-Stereocenters did not epimerize (entry 5), as expected, or did not racemize at all (entries 6 and 7), as checked for $\mathbf{1 f}$ and $\mathbf{1 g}$ by oxidation to the known, corresponding ketones with oxone (Oxone, $2 \mathrm{KHSO}_{5}{ }^{\circ}$ $\mathrm{KHSO}_{4} \cdot \mathrm{K}_{2} \mathrm{SO}_{4}$ ) or with ozone; ${ }^{14}$ the enantiomeric purities of both ketones were confirmed by polarimetry and chiral HPLC (Chiralpak AD-H column).

In parallel experiments with $\mathrm{PBu}_{3}(220 \mathrm{~mol} \%)$, only $70 \%$ of $1 \mathbf{a}$ was obtained after $15 \mathrm{~h}$. With an excess of an aromatic

(9) (a) Davis, F. A.; Zhang, Y.; Andemichae, Y.; Fang, T.; Fanelli, D. L.; Zhang, H. J. Org. Chem. 1999, 64, 1403. (b) Liu, G.; Cogan, D. A.; Owens, T. D.; Tang, T. P.; Ellman, J. A. J. Org. Chem. 1999, 64, 1278.

(10) Annunziata, R.; Cinquini, M.; Cozzi, F. J. Chem. Soc., Perkin Trans. 1 1982, 339.

(11) Boger, D. L.; Corbett, W. L. J. Org. Chem. 1992, 57, 4777.

(12) (a) Davis, F. A.; Friedman, A. J.; Upender, N. K. J. Am. Chem. Soc. 1978, 100, 2844. (b) García-Ruano, J. L.; Alemán, J.; Cid, M. B.; Parra, A. Org. Lett. 2005, 7, 179 and references therein.

(13) (a) Lukin, K. A.; Narayanan, B. A. Tetrahedron 2002, 58, 215. For other related pioneering works (also with $\mathrm{PBu}_{3} / \mathrm{PhSSPh}$ ), see: (b) Barton, D. H. R.; Motherwell, W. B.; Simon, E. S.; Zard, S. Z. J. Chem. Soc., Perkin Trans. 1 1986, 2243 and references therein.

(14) The oxidation of sulfenyl imines with oxone or with ozone was quantitative, and no epimerization of $\alpha$-stereocenters was observed.
Table 1. Conversion of Ketoximes to Sulfenyl Ketimines ${ }^{a}$

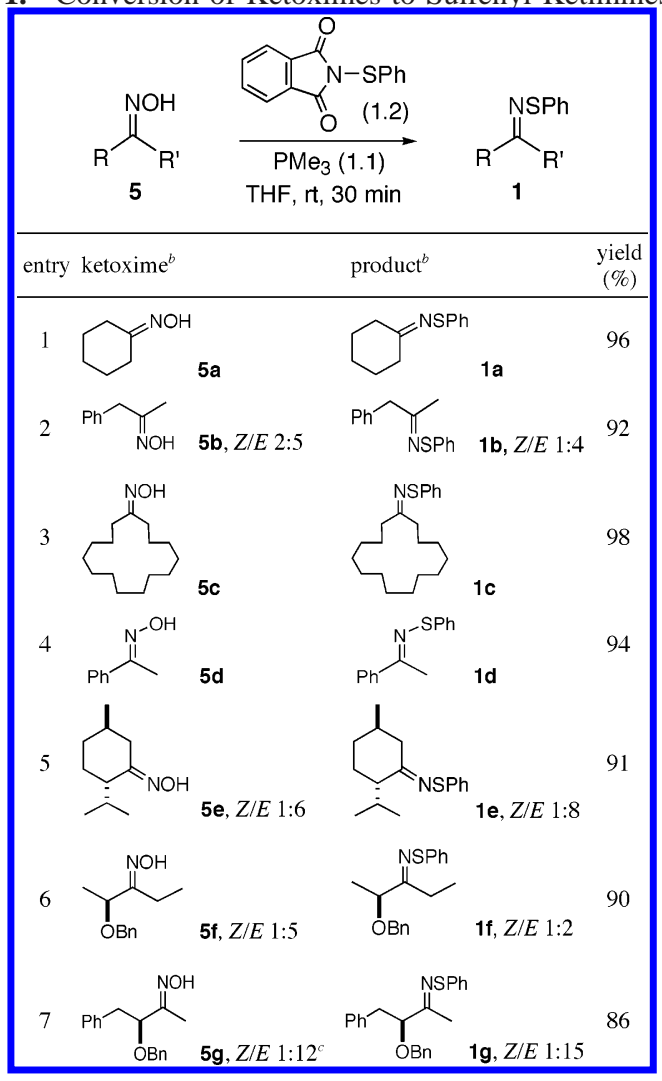

${ }^{a}$ The oxime $(1.0 \mathrm{mmol})$ was added to a commercially available solution of $\mathrm{PMe}_{3}$ in THF (1.0 M, $\left.1.1 \mathrm{~mL}\right)$. PhthN-SPh $(1.2 \mathrm{mmol})$ was added, and the mixture was stirred at $\mathrm{rt}$ for $30 \mathrm{~min} .{ }^{b}$ The $Z / E$ ratios are those observed (400 Mz ${ }^{1} \mathrm{H}$ NMR spectra) in $\mathrm{CDCl}_{3}$ at rt. ${ }^{c}$ Equilibrium mixture from $\mathbf{5 g}$ prepared in pyridine. When the oxime was prepared from $\mathrm{NH}_{3} \mathrm{OH}^{+} \mathrm{Cl}^{-}$and $\mathrm{NaHCO}_{3}$ in $\mathrm{MeOH}-\mathrm{H}_{2} \mathrm{O}$, isomer $Z$ largely predominated.

phosphine, such as $\mathrm{PPh}_{3}$ or $1,1^{\prime}$-bis(diphenylphosphine)ferrocene (dppf), no reaction was observed at $\mathrm{rt}$ after $15 \mathrm{~h}$.

To achieve a total absence of starting materials in the final products, we had to use stoichiometric amounts of PhthN$\mathrm{SPh}$. For example, with 0.4 equiv of PhthN-SPh, only $40 \%$ of the oximes were converted to sulfenimines; with 0.6 equiv of PhthN-SPh, ca. $60 \%$ of conversion occurred. Turnover did not take place, even with an excess of $\mathrm{PMe}_{3}$.

The method partially failed in one case (Scheme 2). When we applied it to oxime $\mathbf{5 h}$, the yield of sulfenimine $\mathbf{1 h}$

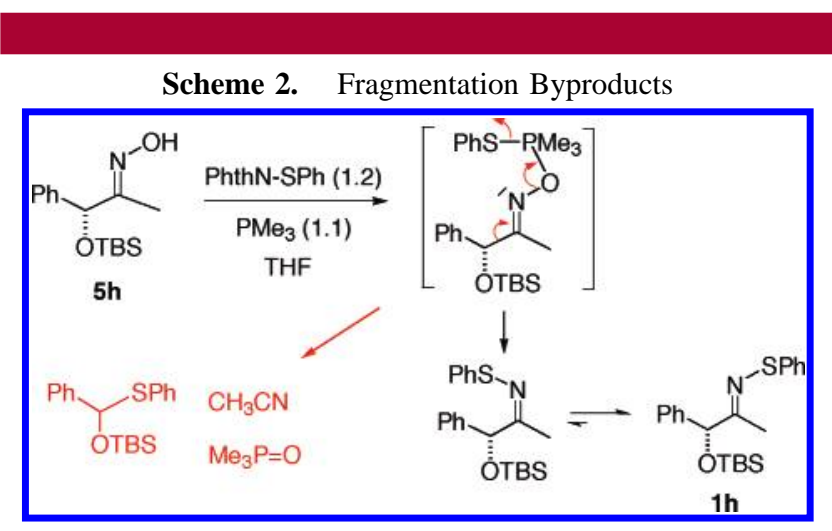


reached a maximum of 70\%. A fragmentation product (the thioacetal shown in Scheme 2) was always formed, even at 0 and $-20{ }^{\circ} \mathrm{C}$, in $20-30 \%$ yields. It may come from the decomposition of the common intermediate via a benzyltype cation, which may be trapped by $\mathrm{PhSH}$. Thus, prone to fragmentation oximes (on protonation or by reaction with electrophiles, giving rise to stable carbenic or oxocarbenic cations) may not afford high yields of sulfenimines $\mathbf{1}$.

Even in this last case (1h), in which the $\alpha$-stereocenter position is benzylic, no racemization took place. In fact, the oxidation of $\mathbf{1 h}$ with oxone gave the corresponding enantiopure ketone, as shown by chiral HPLC.

Secondary nitro groups (6) can also be converted to sulfenimino groups (1) at $\mathrm{rt}$ by the same procedure, using 2.2 equiv of $\mathrm{PMe}_{3}$ instead of 1.1 equiv, as shown in Table 2. One equivalent of $\mathrm{PMe}_{3}$ is consumed in the first step, that

Table 2. From Nitro Compounds to Sulfenyl Ketimines ${ }^{a}$

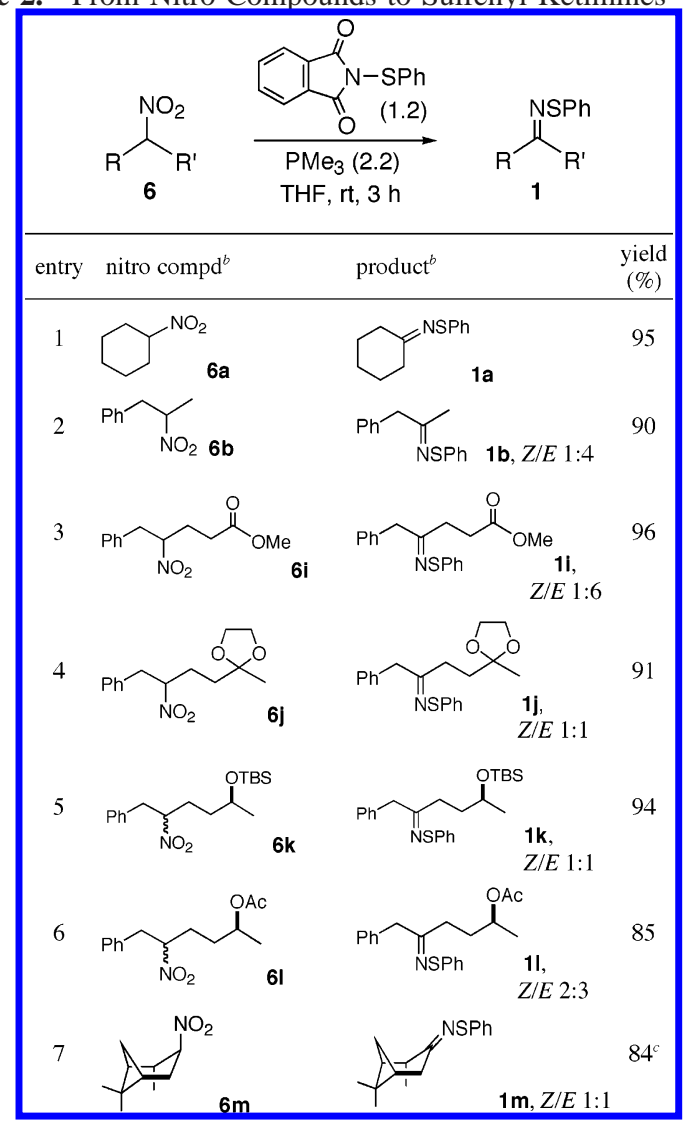

${ }^{a}$ The nitro compound $(1.0 \mathrm{mmol})$ was added to a solution of $\mathrm{PMe}_{3}$ in THF (1.0 M, 1.1 mL). PhthN-SPh $(1.2 \mathrm{mmol})$ was added, and the mixture was stirred at $\mathrm{rt}$ for $30 \mathrm{~min} .{ }^{b}$ The $Z / E$ ratios are those observed (400 Mz ${ }^{1} \mathrm{H}$ NMR spectra) in $\mathrm{CDCl}_{3}$ at rt. ${ }^{c}$ With 3 equiv of PhthN-SPh and 6 equiv of $\mathrm{PMe}_{3}$ for $24 \mathrm{~h}$.

is, the reduction of $\mathrm{R}_{2} \mathrm{CH}-\mathrm{NO}_{2}$ to $\mathrm{R}_{2} \mathrm{CH}-\mathrm{N}=\mathrm{O} / \mathrm{R}_{2} \mathrm{C}=\mathrm{N}-$ $\mathrm{OH}$ catalyzed by $\mathrm{PhthN}-\mathrm{SPh}$, which is slower than the second step, the sulfenylation of the oxime group. After $1-3 \mathrm{~h}$ of reaction, sulfenimines 1 were isolated in excellent yields. Stereocenter $\alpha$ of $\mathbf{1 m}$ did not epimerize.

To our knowledge, this is the first reported method for obtaining $N$-sulfenyl imines directly from nitro compounds.
Moreover, the reaction works in one pot, at rt, in a short time, and using very small amounts of commercially available reagents. The only exception was converting $\mathbf{6} \mathbf{m}^{15}$ to $1 \mathrm{~m}$, as 3.0 equiv of $N$-(phenylsulfenyl)phthalimide, 6.0 equiv of $\mathrm{PMe}_{3}$, and $24 \mathrm{~h}$ were needed to obtain a good yield.

To gain more insight into the mechanism, the reaction of nitrocyclohexane (6a) with 3 equiv of $\mathrm{PMe}_{3}$ and 0.2 equiv of PhthN-SPh was followed by ${ }^{13} \mathrm{C}$ NMR spectroscopy in THF (Figure 1). ${ }^{16}$ For the sake of simplification, only the

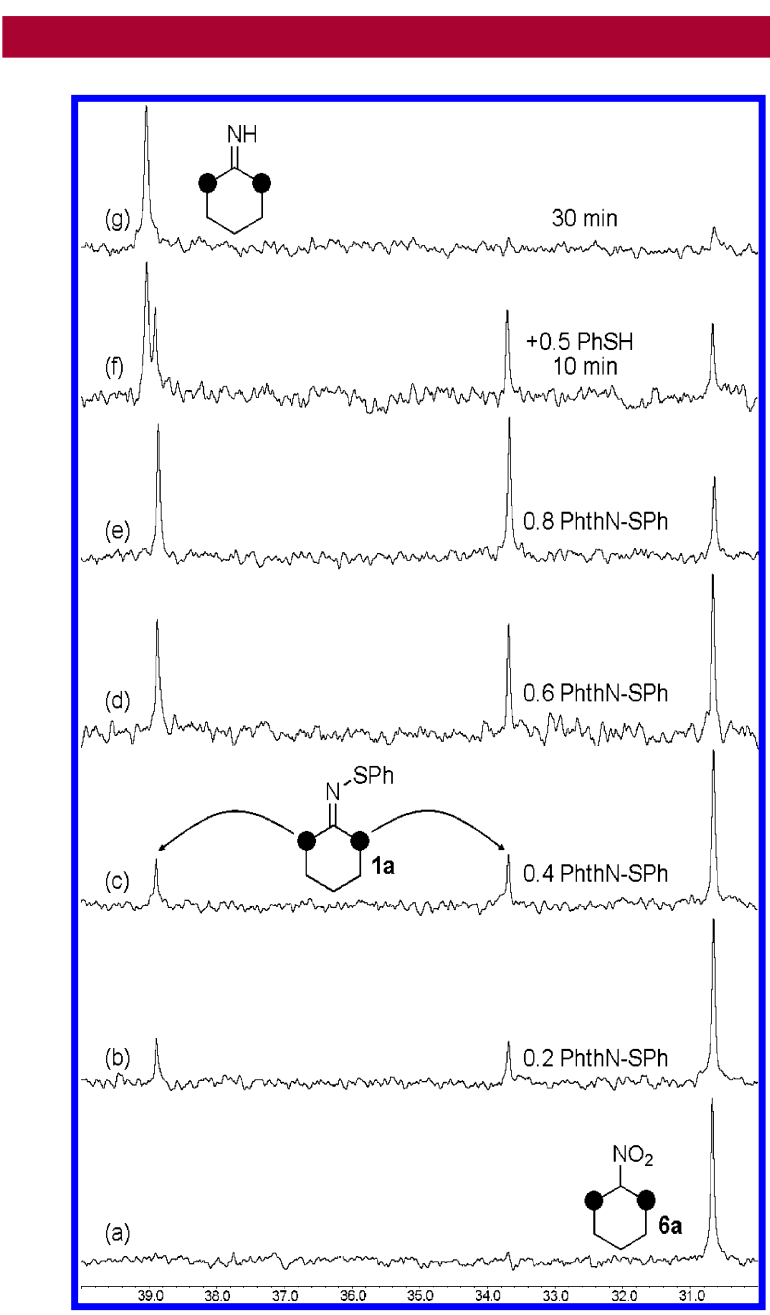

Figure 1. (a) ${ }^{13} \mathrm{C}$ NMR spectra of nitrocyclohexane (6a) and excess of $\mathrm{PMe}_{3}$ ( 3 equiv) in THF. (b-e) After successive additions of 0.2 equiv of PhthN-SPh, only the appearance of sulfenimine 1a was observed. (f) Addition of 0.5 equiv of $\mathrm{PhSH}$ to (e); spectrum registered after $10 \mathrm{~min}$. (g) Spectrum registered $30 \mathrm{~min}$ after the addition of 0.5 equiv of $\mathrm{PhSH}$.

signals of the methylene carbons vicinal to the $\mathrm{CH}-\mathrm{NO}_{2} /$ $\mathrm{C}=\mathrm{NOH} / \mathrm{C}=\mathrm{NSPh}$ groups are shown. The disappearance of the oxime intermediate was so quick that it could not be detected under these conditions.

However, even with large amounts of $\mathrm{PMe}_{3}$, sulfenimine (1a) was not cleaved. In fact, acidic species must be present

(15) (a) Cooper, D. G.; Jones, R. A. J. Chem. Soc. (C) 1971, 3920. (b) Murray, R. W.; Singh, M.; Rath, N. Tetrahedron: Asvmmetry 1996, 7, 1611. (16) For an excellent description of No-D NMR, see: Hoye, T. R.; Eklov, B. M.; Ryba, T. D.; Voloshin, M.; Yao, L. J. Org. Lett. 2004, 6, 953. 
in the reaction media or water must be added to catalyze or mediate such a $\mathrm{N}-\mathrm{S}$ bond cleavage. ${ }^{13 \mathrm{a}}$

Thus, "the secret of the success" is that the phthalimide anion of $\left[\mathrm{PhthN}^{-} \mathrm{PMe}_{3}(\mathrm{SPh})^{+}\right]$traps the oxime proton, but PhthNH, in contrast to ArSH, is not acidic enough to help the conversion of sulfenimines $\mathbf{1}$ to ketimines.

It is likely that many other aromatic and heteroaromatic phthalimide derivatives (PhthN-SAr or PhthN-SHet) may behave similarly. On the other hand, PhthN-S ${ }^{t} \mathrm{Bu}$ does not work, as no reaction with nitroalkanes or oximes was observed under our conditions; thus, our method is not useful for the preparation of Ellman's substrates. ${ }^{1 c}$

In summary, efficient and mild conditions (short times, rt, 84-98\% yields) for the conversion of ketoximes and secondary nitro compounds to sulfenyl ketimines (1) have been uncovered. No epimerization of $\alpha$-stereocenters takes place. The role of $\mathrm{PMe}_{3}$ is outstanding (in relation to $\mathrm{Bu}_{3} \mathrm{P}$ and aromatic phosphines). In principle, a plethora of arylsulfinyl ketimines (2), arylsulfonyl ketimines (3), and arylsulfonyl oxaziridines (4) are available via the new route.
Acknowledgment. The Ministerio de Educación y Ciencia of Spain (Madrid) is acknowledged for the grants SAF0202728 and CTQ2006-15393 as well as for a studentship to J.B. The Universitat of Barcelona is acknowledged for a studentship to C.I. The Generalitat de Catalunya (Barcelona) contributed also partially (grant 2001SGR065, 2002-2005, Grup de Síntesi Estereoselectiva d'Antibiòtics i Antivírics). The ketone of $\mathbf{5 f}$ was prepared by Carmen Jiménez, of our Department. The senior author dedicates this work to Prof. Joan Bosch (Facultat de Farmàcia, Universitat de Barcelona) on the occasion of his 60th birthday.

Supporting Information Available: Experimental procedures and NMR spectra of the new compounds. This material is available free of charge via the Internet at http://pubs.acs.org.

OL702212N 